\title{
$\sqrt{6}$ ACUAYTERRIORIO
}

\section{Depuración y reutilización de aguas en España}

\section{Wastewater Treatment and Water Reuse in Spain}

\author{
J oaquín Melgarejo-Moreno \\ Instituto del Agua y de las Ciencias Ambientales, Universidad de Alicante. Alicante, España. jmelgar@ua.es
}

M. a Inmaculada López-Ortiz

Universidad de Alicante. Alicante, España. iortiz@ua.es

Resumen - El tema de la depuración y la reutilización de las aguas es de gran trascendencia, sobre todo en los espacios donde la escasez de recursos convencionales es un problema estructural, como es el caso de España. El potencial que presenta este recurso no convencional, estratégico en las situaciones de déficit, es incuestionable; máxime si se tiene en cuenta en el marco de la planificación y bajo el supuesto de un modelo de explotación hídrica que tenga como objetivo prioritario la conservación, protección y mejora de la calidad del agua, y la utilización sostenible y eficiente de los recursos naturales. En el trabajo se pone de manifiesto cómo depuración y reutilización van ligadas, ya que la reutilización de aguas residuales está asociada a una regeneración previa, y son dos herramientas esenciales del modelo ambiental del agua, tal como lo preconiza la normativa comunitaria. El ingreso de España en las instituciones europeas ha sido un revulsivo en los temas ambientales, por cuanto ha supuesto la exigencia de adaptar al país a la normativa europea, mucho más exigente. El esfuerzo realizado ha sido importante, pero todavía estamos lejos de cumplir con todos los requerimientos de Europa.

Abstract - The issue of wastewater treatment and the reuse of water is of great importance, especially in areas where the shortage of conventional resources is a structural problem, as it is in the case of Spain. The likelihood that this unconventional, strategic resource would become scarce is unquestionable, particularly in cases where water planning and exploitation systems prioritize the preservation, protection and improvement of water quality, as well as the sustainable and efficient use of natural resources. This paper shows how wastewater treatment and reuse are linked, as the reuse of wastewater is associated with a previous regeneration, and both of them are essential tools for maximizing environmental outcomes, as called for in the European Union Directives.

Palabras clave: depuración, reutilización de aguas, España

Información Artículo: Recibido: 14 marzo 2016

Revisado: 12 septiembre 2016

Aceptado: 19 octubre 2016

(c) Universidad de J aén / Seminario Permanente Agua, Territorio y Medio Ambiente (CSIC) 


\section{INTRODUCCIÓN ${ }^{1}$}

Las aguas depuradas regeneradas deben considerarse como un recurso no convencional, cuya gestión debe incluirse en una planificación integral de los recursos hídricos, que tenga en cuenta los aspectos económicos, sociales y ambientales. La reutilización puede incrementar los usos del agua ya utilizada, aumentando la disponibilidad de recursos hídricos. El agua regenerada puede sustituir usos que no requieran una calidad elevada, liberando volúmenes de mejor calidad para otros usos más exigentes. Las limitaciones ambientales y las sequías plurianuales han Ilevado a numerosas poblaciones a plantearse la utilización de aguas depuradas como fuente adicional de agua para aprovechamientos que no requieran una calidad de agua potable.

Los beneficios de la reutilización se manifiestan principalmente en el incremento de los recursos disponibles, teniendo en cuenta además que, frente a otros recursos alternativos, las aguas regeneradas presentan unas importantes ventajas. Son un recurso estable al estar condicionado por el abastecimiento. Son más baratas que las obtenidas mediante trasvases o desalinización, ya que su producción consume menos energía que los anteriores métodos de incremento de la oferta. Con los tratamientos actuales, su calidad es suficiente para la mayoría de los usos, por lo que carece de sentido usar agua de mejor calidad para el riego u otras actividades con un coste excesivo. Esto permite liberar recursos de mejor calidad para el abastecimiento mediante el intercambio con los regantes, reservando el agua potable para usos domésticos². Del mismo modo, la utilización de aguas regeneradas permite reducir la explotación de acuíferos sobreexplotados o con problemas de intrusión, especialmente marina en áreas costeras. En muchas ocasiones, tras el tratamiento adecuado, estas aguas se están utilizando para proporcionar caudales ecológicos o volúmenes ambiental es ${ }^{3}$. También pueden utilizarse en usos industria-

1 Este trabajo ha sido financiado en parte por la Fundación Séneca-Agencia de la Ciencia y la Tecnología, con cargo al Proyecto "El papel de los mercados del agua en la gestión integrada de los recursos hídricos en las cuencas deficitarias" (Ref. 19325/ PI/ 15).

2 Un ejemplo de probada eficacia lo encontramos en la comarca de la Marina Baja (Alicante), donde se vienen realizando permutas entre la agricultura y el abastecimiento a través del Consorcio de Aguas de la Marina Baja. El Consorcio de Aguas es el garante del abastecimiento en alta de la mayor parte de la población de la comarca desde 1968. Ha sabido articular, junto a los regantes, un sistema de intercambio de caudales que garantizan la "suficiencia" de recursos globales del sistema. Los regantes acceden a no utilizar o liberar aguas blancas que por derecho les corresponden según las concesiones otorgadas, utilizándose las mismas para satisfacer las necesidades de abastecimiento de los municipios costeros. A cambio, el Consorcio se compromete a enviarle a los regantes caudales depurados en buenas condiciones de calidad procedentes de las EDAR de la comarca para atender a las necesidades de regadío, o a financiar las obras y gastos corrientes de aquellas otras Comunidades que no aceptan estos caudales. El equilibrio del sistema lo completa una transferencia de recursos, bien como aportaciones directas del Consorcio a los presupuestos de las Comunidades de regantes, bien a través de pago de facturas energéticas en su nombre y mantenimiento de infraestructuras, que ha sido desde los años setenta, y lo sigue siendo en la actualidad, favorable para todas las partes implicadas. De esta forma, el análisis de la demanda urbana de agua no puede ir separado del estudio de la demanda agrícola y viceversa, tanto si el consumo es de caudales blancos, como si analizamos el consumo de aguas depuradas, ya que el sistema funciona de forma integrada (Melgarejo et al, 2015)

3 Es el caso del agua proporcionada por la EDAR de Pinedo en Valencia, que permite reutilizar $78 \mathrm{hm}^{3} /$ año para emplearlos en el regadío y en la restauración medioambiental del Parque Natural de la Albufera. les o recreativos. Debe tenerse en cuenta, además, que el uso de aguas regeneradas en la agricultura disminuye el consumo de fertilizantes, al aprovechar los nutrientes que estos recursos pueden aportar. Asimismo, proporciona alternativas al vertido del agua depurada en zonas en que este resulta complicado, y contribuye a la depuración del agua cuando se utiliza como filtro verde, al eliminar sustancias más difícilmente biodegradables. Los tratamientos para la regeneración incrementan la garantía sanitaria en aquellas zonas en las que ya venían siendo utilizadas las aguas residuales con inferior tratamiento para el riego; mejoran la productividad de los cultivos, al eliminarse sustancias perjudiciales, y eliminan la contaminación por vertido al dominio público, en caso de no reutilización directa.

Asociados a estas ventajas hay que señalar otros beneficios indirectos que pueden obtenerse como la demanda de actividad en el sector de la construcción y la creación de empleo que conlleva el esfuerzo inversor en infraestructuras y el mantenimiento de la agricultura y sus valores ambientales, sociales y patrimoniales. En definitiva, las aguas regeneradas reutilizadas rentabilizan los procesos de depuración y aportan tecnología y una posición de vanguardia en la gestión racional de los recursos hídricos disponibles.

\section{Situación de La dePURACIÓn Y REUTILIZACIÓN En España}

La política ambiental europea tiene entre sus principios fundamentales la conservación, protección y mejora de la calidad del agua, así como la utilización prudente y racional de los recursos naturales. Para la consecución de dichos objetivos se han seguido diferentes estrategias en el transcurso del tiempo, que han ido desde la protección de los recursos hídricos en función de los usos del agua (objetivos de calidad), al control de vertidos mediante normas de emisión, para llegar a una estrategia ambiental basada en la protección de las masas de agua consideradas como ecosistemas acuáticos, con un enfoque, por tanto, más ambiental, que promueve e impulsa un uso más sostenible del agua 4 .

Con la aprobación de la Ley de Aguas en 1985 se inicia una nueva visión en relación con el control de la contaminación, al incluir una serie de estipulaciones que significaron un cambio de planteamiento en relación con los vertidos. Los aspectos más rele-

4 La Administración hidráulica hizo sus primeras aproximaciones al problema de control de la contaminación al clasificar los ríos españoles en protegidos, vigilados, normales e industriales, con una calidad de referencia decreciente, lo que en teoría significaba que los vertidos debían ser controlados en función de la tipología del cauce al que vertían, que a su vez estaba relacionada con los potenciales usos del agua en cada caso (Circulares del MOPU en 1959 y 1960). La realidad distó bastante de lo que se pretendía con ese primer intento de controlar los vertidos y, ya en la década de los setenta, fue el Centro de Estudios Hidrográficos del CEDEX el que elaboró unas Recomendaciones (1974) para el Diseño de Instalaciones de Depuración. De esta manera, se prescribió, quizá por primera vez con carácter general, que los tratamientos de depuración propuestos debían cumplir unas condiciones para la calidad del efluente con carácter orientativo que podrían ser revisadas para casos especiales (Cajigas, 2012). De aquella década de los setenta se pueden destacar los planes especiales de la Costa Brava (1971) y de las Islas Baleares (1972), que representaron el inicio de significativas actuaciones en el litoral español, cuyo obj etivo no era otro que mejorar la situación de las playas $y$, por tanto, ofrecer una adecuada infraestructura sanitaria para el desarrollo de la actividad turística. 


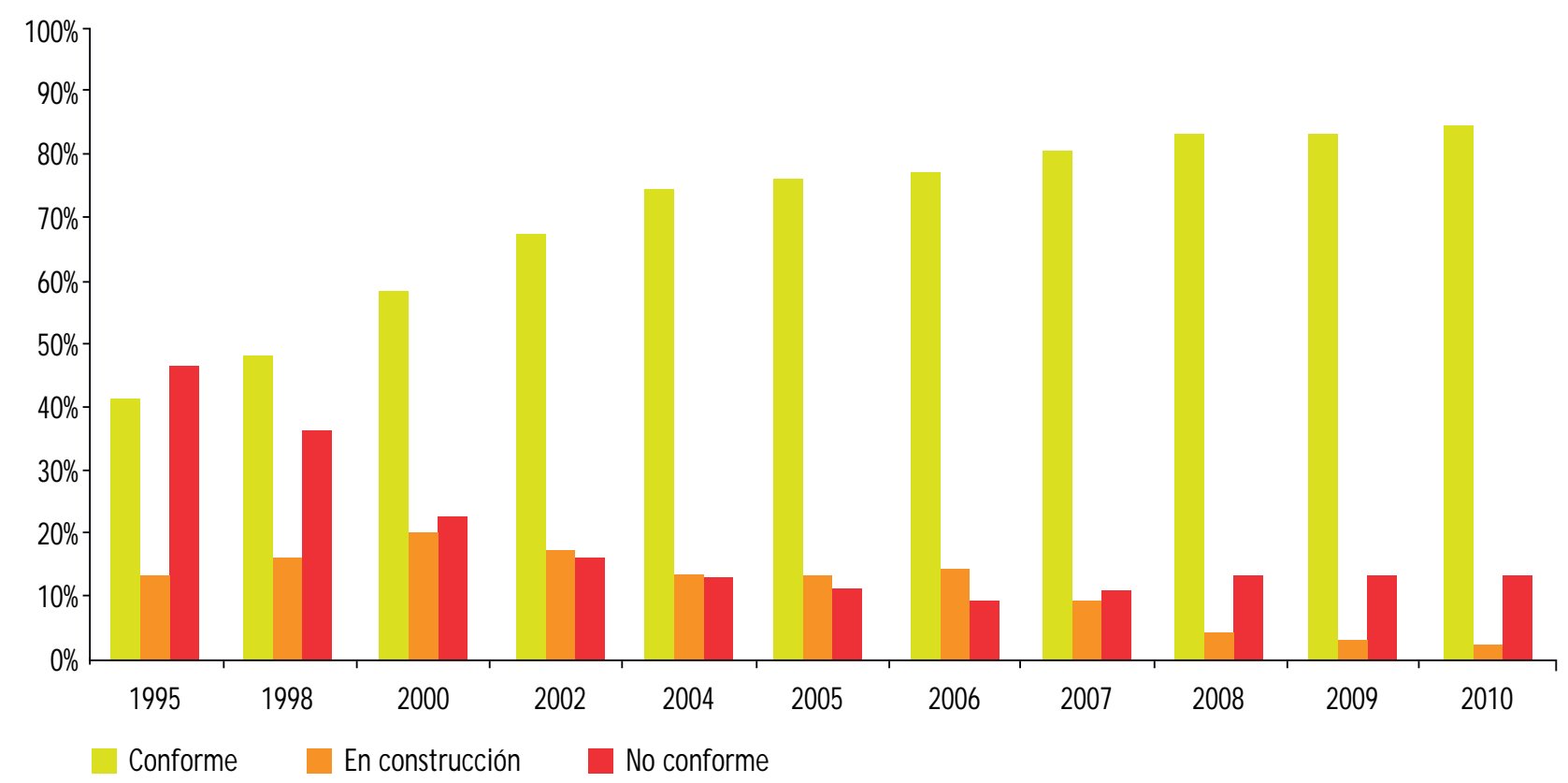

Fuente: Elaboración OSE a partir del MAGRAMA, 2012.

vantes de esa nueva estrategia fueron: a) "Todos los vertidos capaces de provocar contaminación requieren una autorización", lo que se traducía en la práctica en la exigencia de llevar a cabo medidas correctoras para minimizar su impacto en el medio. b) Los vertidos irán gravados con un canon en función de su tipología y características contaminantes. c) El incumplimiento de los límites impuestos en la autorización llevaría consigo un expediente sancionador por daños al dominio público hidráulico. Pese a la citada regulación, para que realmente fuera de verdadera aplicación lo estipulado, había que esperar a la aprobación de los Planes Hidrológicos de Cuenca (PHC), por ser estos los que establecerían las "características básicas de calidad de las aguas y la ordenación de los vertidos de aguas residuales". Es decir, las autorizaciones de vertido carecían de referente cierto mientras no se concretaran en los PHC los objetivos de calidad de acuerdo con los usos del agua ${ }^{5}$.

El nuevo enfoque dado por la Ley de Aguas pronto se vio sobrepasado al incorporarse España a la CEE en 1986 y tener que cumplir con el elenco normativo europeo en materia de calidad de aguas. Primero, fueron las Directivas de objetivos de calidad 0 de primera generación (baños, vida piscícola, prepotables, etc.) y, después, las de segunda generación (normas de emisión), cuyo principal exponente fue la Directiva 91/271 sobre depuración de aguas residuales urbanas 6 .

5 Cajigas, 2012.

6 Directiva 91/ 271/ CEE del Consejo, de 21 de mayo de 1991, sobre el tratamiento de las aguas residuales urbanas. Diario Oficial $n .0-L 135$ de 30 de mayo de 1991. La Directiva 91/271/CEE establecía las medidas necesarias que los Estados miembros habían de adoptar para garantizar que las aguas residuales urbanas recibieran un tratamiento adecuado antes de su vertido, con la finalidad de reducir los niveles de contaminación de las aguas superficiales. Esta Directiva señala dos obligaciones diferenciadas: el diseño y construcción de colectores que recojan las aguas residuales generadas por las aglomeraciones urbanas y los distintos tratamientos a los que se debían someter las aguas residuales antes de su vertido, en función de las características de la zona de vertido. Las zonas se clasifican en
En España, la depuración a gran escala se inicia con el Plan Nacional de Saneamiento y Depuración 1995-2005 (PNSD), que tenía como principal objetivo cumplir la Directiva 91/271CEE, que establecía calidades de vertido de aguas residuales tratadas en función de la zona de vertido ${ }^{7}$. El PNSD fue elaborado para coordinar las actuaciones de las administraciones públicas en esta materia, dado que es competencia autonómica. Durante su período de implantación, se pasó de un volumen de 0,13 $\mathrm{m}^{3} /$ habitante/ día de aguas residuales tratadas en 1996 a 0,31 en 2006. El dato más reciente, del año 2011, cifra el volumen de aguas residuales tratadas en 13,5 hm³ / día, y principalmente se producen en AndaIucía, Cataluña, Madrid y Valencia8.

En 2006 el grado de conformidad con las exigencias de tratamiento de la Directiva para las depuradoras de toda España era del $76 \%$ con un $13 \%$ adicional de tratamientos en ejecución y un $11 \%$ de casos no conforme (por tratamiento inadecuado o no tratamiento). Durante el periodo 1995-2010, España solo depuró el $84 \%$ de sus aguas residuales; y aunque la población equivalente no conforme experimentó un descenso considerable, situándose en 2010 en un total de 10.909.722 h-e (16\%), el esfuerzo realizado no ha sido suficiente ${ }^{9}$. A España le quedaba en esa fecha todavía

"sensibles", "menos sensibles" o "normales", y, de acuerdo a esta clasificación, los tratamientos serán más o menos rigurosos. Los tipos de tratamiento se clasifican en tratamiento primario, tratamiento secundario, tratamiento más riguroso y tratamiento adecuado. En 2006 se produjo una nueva declaración de zonas sensibles y, como consecuencia, se tuvieron que adaptar muchas instalaciones para cumplir con los requisitos de reducción de nutrientes.

7 Resolución de 28 de abril de 1995, de la Secretaría de Estado de Medio Ambiente y Vivienda, por la que se dispone la publicación del Acuerdo del Consejo de Ministros de 17 de febrero de 1995, por el que se aprueba el Plan Nacional de Saneamiento y Depuración de Aguas Residuales. Ministerio de Obras Públicas, Transporte y Medio Ambiente. B. O.E. n. -113 , de 12 de mayo de 1995.

8 MAGRAMA, 2014.

9 Porcentaje de habitantes equivalentes con tratamiento de aguas residuales según los obj etivos fijados por la Directiva comunitaria 91/271/ CE respecto al 
Gráfico 2. Grado de conformidad con la Directiva 91/271/CEE por Comunidades Autónomas, 2010

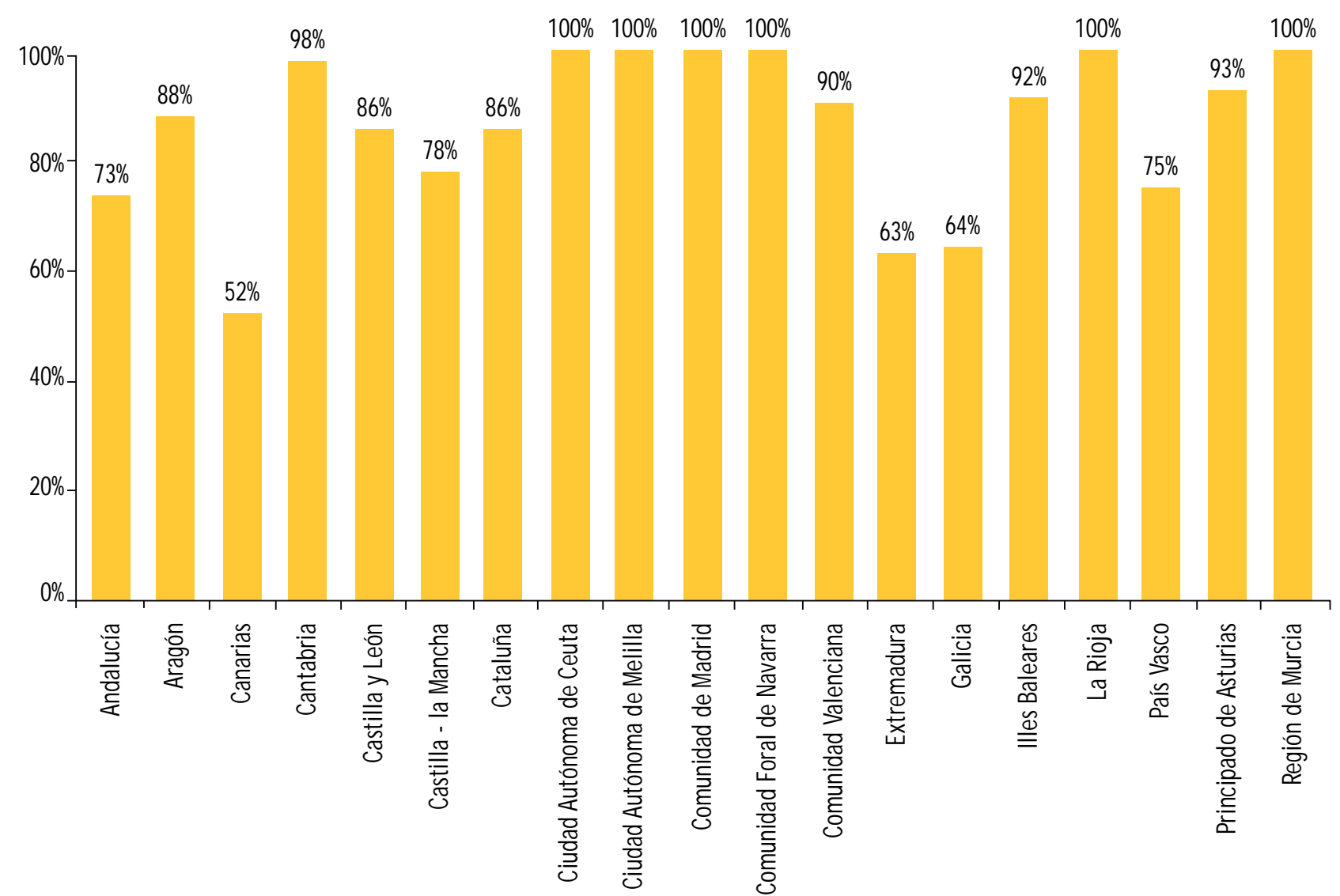

Fuente: Elaboración OSE a partir del MAGRAMA, 2012.

mucho por hacer para poder cumplir con el objetivo marcado por la Unión Europea a través de la Directiva 91/271/CE. La evolución del grado de cumplimiento o conformidad de España con la normativa europea de depuración puede verse en el gráfico 1. En él queda evidenciado el avance notable que ha experimentado el país como consecuencia de la aplicación del PNSD.

Según el MAGRAMA ${ }^{10}$, la Comunidad de Madrid, Comunidad Foral de Navarra, Región de Murcia, La Rioja y las ciudades autónomas de Ceuta y Melilla eran las regiones con mayor grado de conformidad con la Directiva 91/271/CE, cumpliendo con el $100 \%$ por el contrario, Canarias con un 52\% era la región con el porcentaje más bajo (gráfico 2). Por demarcaciones hidrográficas, Tajo, Guadiana y Guadal quivir eran, en 2011, las que presentaban peor calidad del agua. Miño-Sil, Ebro, Galicia Costa, Cantábrico occidental y oriental y Júcar fueron las demarcaciones donde todas las estaciones de control indicaron valores con menor contaminación.

El PNSD contemplaba inversiones por valor aproximado de 1,9 billones de pesetas de 1995 (11,4 miles de millones de euros, según los datos facilitados por las Comunidades Autónomas en 1995 y contrastados entonces por la Secretaría de Estado

\footnotetext{
total de habitantes equivalentes. Mide el nivel de depuración y la eficiencia del sistema de depuración existente en una cuenca hidrográfica 0 en un territorio determinado.
}

10 MAGRAMA, 2012 de Medio Ambiente y Vivienda del MOPTMA), con los que había que financiar todas las necesidades en materia de saneamiento y depuración, con intervención de las tres administraciones con competencias (estatal, autonómica y local). El Plan preveía como aportación de la Administración General del Estado (AGE) para cada Comunidad Autónoma un $25 \%$ de toda la inversión que fuese precisa en actuaciones que se declaraban de interés general, dejando por lo tanto el 75\% restante a las Comunidades Autónomas que debían acometer las inversiones antes del 31 de diciembre de $2005^{11}$. Un elemento clave radicaba en asegurar la adecuada gestión de las instalaciones (explotación y mantenimiento de los sistemas de depuración) para evitar su fracaso una vez construidas las plantas. Para ello, la AGE recomendaba a las Comunidades Autónomas que creasen entes supramunicipales de gestión que, bien de forma directa 0 a través de empresas especialistas, se hicieran cargo de la operación de las instalaciones. Además, todo ello conllevaría la generalización del cobro del denominado canon de saneamiento, con la finalidad de que este permitiera al menos cubrir los costes de explotación e incluso pudiera servir como instrumento clave para la financiación de las plantas que

11 MAGRAMA, 2007. No obstante, el éxito de la financiación del Plan estuvo en la aportación de los Fondos Europeos (Cohesión y Feder), ya que la mayor parte de las estaciones depuradoras contaron con estas ayudas (en algunos casos de hasta el 80 u $85 \%$. Puede afirmarse que más de la mitad de las ejecuciones del Plan se aprovecharon de los recursos europeos (Cajigas, 2012). 
debían acometer las autonomías en el marco de los acuerdos del PNSD ${ }^{12}$. En definitiva, el Plan ha marcado un hito en el desarrollo de la depuración en España, ya que ha permitido, desde su aprobación en 1995 hasta el año fijado en la Directiva (2005), la construcción de más de setecientas depuradoras, lo que ha elevado el nivel de cobertura por encima del $80 \%$ y ha supuesto una notable mejora en la calidad del agua de los ríos y del litoral. La situación del cumplimiento de la Directiva 91/271/ CEE en 2013 puede observarse en el gráfico 3.

Gráfico 3. Cumplimiento de la Directiva 91/271/ CEE en España, 2013

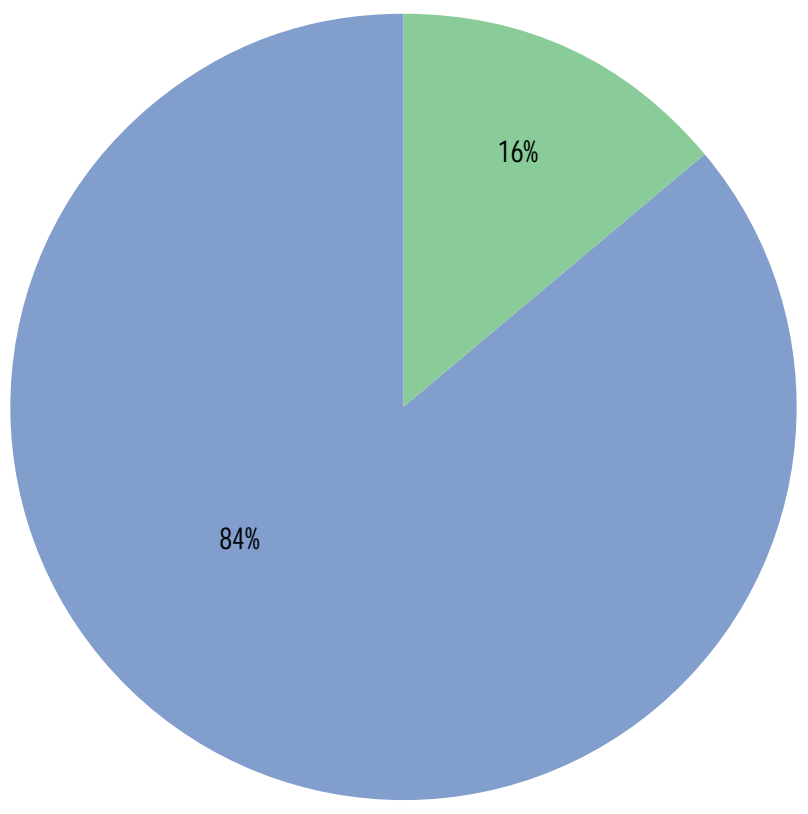

Carga No Conforme 11.129.112 h-e

Carga Conforme 57.402.876 h-e

Fuente: Torres, 2014.

En 2007 se aprobó el Plan Nacional de Calidad de las Aguas: Saneamiento y Depuración 2007-2015 (PNCA), que tenía como objetivo fundamental lograr la plena conformidad con la Directiva 91/ 271CEE y la Directiva Marco del Agua, así como cubrir las necesidades futuras en materia de saneamiento y depuración ${ }^{13}$. El presupuesto total asignado para este programa ascendía a 19.645 $M €$, que se distribuían en diferentes actuaciones, tal como queda

12 Muchas Comunidades Autónomas, sensibles a la dificultad que supondría la gestión de numerosas instalaciones, abordaron la creación de entidades gestoras como ESAMUR en Murcia, EPSAR en Valencia, ACA en Cataluña, en Madrid es el Canal de Isabel II quien cumple esa función, NILSA en Navarra y otras en Baleares, Rioja, Galicia, Aragón y País Vasco; de manera que mediante el cobro de un canon de saneamiento (desigual en su cuantía) han podido acometer el mantenimiento y la explotación de cientos de depuradoras (en algunos casos también su construcción), contribuyendo así al éxito del Plan de Depuración y al cumplimiento de la normativa europea

13 El Ministerio de Medio Ambiente, en colaboración con las Comunidades Autónomas, realizó el Plan Nacional de Calidad de las Aguas: Saneamiento y Depuración 2007-2015, con el propósito de alcanzar los objetivos que no se habían cubierto con el anterior (que había logrado un nivel de conformidad del $77 \%$ ) y para dar respuesta a las nuevas necesidades planteadas por la Directiva Marco del Agua y por el Programa AGUA. reflejado en la tabla 1 . Del total de la inversión estimada, el Ministerio de Medio Ambiente se comprometía a aportar 6.233 M€; de los cuales, 3.046 eran heredados del primer Plan de Saneamiento, 1.777 estaban asociados a nuevos compromisos de intervención y 1.430 eran de financiación recuperable en 45 años a través de las Sociedades Estatales. Sin embargo, la crisis económica que ha atravesado el país desde 2008 no ha permitido que se ejecuten la mayor parte de estas inversiones ${ }^{14}$.

Los objetivos básicos perseguidos por el PNCA eran los siguientes: 1) Definir y asegurar los caudales ambientales. 2) Proteger la biodiversidad y los dominios públicos hidráulicos y marítimo-terrestres como territorio. 3) Gestionar los dominios públicos hidráulico y marítimo terrestre para asegurar la calidad y el buen estado de las masas de agua superficiales, subterráneas, de transición y costeras. 4) Garantizar el abastecimiento a las poblaciones. 5) Fomentar la participación pública y asegurar una administración del agua transparente. 6) Potenciar la concertación, cooperación y coordinación interadministrativa para mejorar la dotación y los niveles de servicios a la población. 7) Proteger los derechos de las generaciones actuales y futuras a un agua de calidad y a la conservación de los ecosistemas y del rico y abundante patrimonio natural español.

El PNCA preveía que, en 2015, unos mil doscientos $\mathrm{hm}^{3} /$ año -es decir, el $34 \%$ de los aproximadamente $3.500 \mathrm{hm}^{3} /$ año del total de agua residual tratada ese año- fuese adecuadamente generada y estuviese potencialmente disponible para reutilización ${ }^{15}$. En 2012 España tenía un nivel de depuración comparable a los países que forman parte de la UE, situándose en la media en relación con los sistemas de depuración convencionales, aunque por debajo en lo que se refiere a las zonas sensibles y también a las pequeñas y medianas aglomeraciones ${ }^{16}$. Sin embargo, aunque la Comisión Europea reconoce la "solución de algunos problemas" identificados en sistemas de depuración de agua, señala que España sigue "rezagada" en la aplicación de la normativa común. Se trata básicamente de incumplimientos que afectan a "zonas sensibles", es decir, enclaves en los que las exigencias de depuración son mayores por tratarse de áreas con valor ecológico 0 "destinadas a la obtención de agua potable", tal como establece la directiva sobre el tratamiento de las aguas residuales urbanas

14 El MAGRAMA ha reducido las necesidades inversoras urgentes hasta el 2020 a casi la mitad, cifrándolas en 10.000 M€. Según el informe de la consultora Price Water House Coopers (2014) sobre la gestión del agua en España, durante el periodo 2013-2021, las necesidades de inversión del sector del agua ascenderían a 15.700 M€, de los cuales 13.700 M€ se dedicarían a saneamiento, alcantarillado y depuración (AEAS, 2015).

15 En cuanto a la distribución por usos del agua depurada, en 2007, un 75\% se destinaba para uso agrícola, el 12\% para usos recreativos y campos de golf, el $6 \%$ para servicios urbanos, el $4 \%$ para usos ecológicos y recarga de acuíferos, y en torno al 3\%era para uso industrial.

16 España cumple la Directiva 91/271 en un 84\% según el último informe entregado a Europa correspondiente al año 2013. Sin embargo, discerniendo el cumplimiento por artículos, se observa que en el artículo 5, que corresponde al tratamiento más riguroso en vertidos a Zonas Sensibles con eliminación de Nitrógeno y Fósforo, España cumple solo entre el 40\% y el 60\% Aproximadamente setecientas aglomeraciones urbanas tienen abierto un proceso de infracción por incumplimiento y otras 200 están detectadas como potenciales infractoras. 
Tabla 1. Actuaciones previstas y valoración económica de las mismas en el Plan Nacional de Calidad de las Aguas: Saneamiento y Depuración, 2007-2015

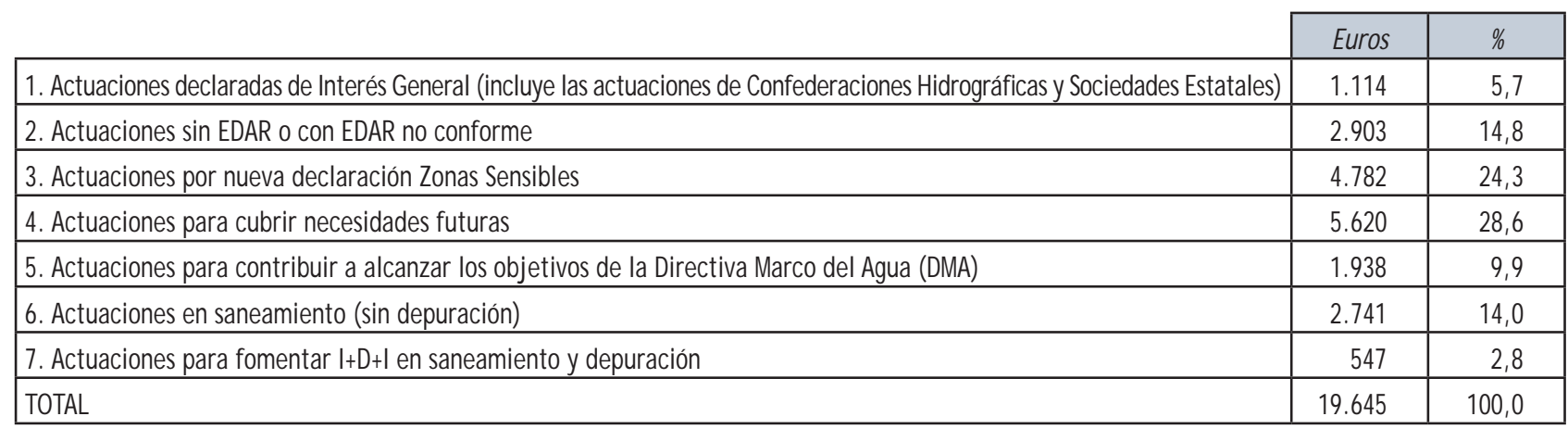

Fuente: MIMAM, 2007.

de $1991^{17}$. Una parte importante del incumplimiento de España se debe a la gran cantidad de zonas sensibles del país, ya que el $27,2 \%$ del territorio nacional está incluido en la Red Natura 2000, lo que ha supuesto un incremento de las necesidades de depuración de unas doscientas poblaciones, con un coste asociado superior a los $2.200 \mathrm{M}$.

En 2003, casi cinco años después de que concluyese el plazo máximo para la instalación de los sistemas de depuración de aguas residuales, España recibió el primer aviso europeo por insuficiente tratamiento de las aguas en varias localidades. La amonestación se repitió en 2008. En 2011 el Tribunal de Justicia de la Unión Europea condenó a España por incumplir la Directiva 91/271/CE, al no haber adoptado las medidas necesarias en relación con la recogida y tratamiento de las aguas residuales urbanas de numerosas aglomeraciones españolas de más de 15.000 habitantes. En noviembre de 2014, la Comisión Europea de nuevo denunció a España ante el Tribunal de J usticia de la Unión Europea (TJUE) por no garantizar el "correcto tratamiento" de las aguas residuales urbanas en varios municipios de Galicia y Cataluña, y por haber remitido información "incompleta" o no haber cumplido los niveles óptimos en poblaciones de Andalucía y Cataluña. En 2015 los procedimientos abiertos contra España por incorrecta depuración afectaban a 800 núcleos de población repartidos por toda la geografía nacional ${ }^{18}$. En abril de ese mismo año, el Tribu-

17 La determinación de las zonas sensibles depende del Estado para las cuencas hidrográficas intercomunitarias y de las Comunidades Autónomas para las cuencas intracomunitarias y las aguas costeras. Una vez declarada zona sensible, el plazo para cumplir los requisitos correspondientes son siete años y las revisiones de zonas "sensibles" y "menos sensibles" se deben hacer cada cuatro años, de acuerdo al artículo 5.6 de la Directiva 91/271/ CEE. En 1998 se declararon las zonas sensibles de las cuencas hidrográficas intercomunitarias y se identificaron las aglomeraciones afectadas. En los años siguientes, las Comunidades Autónomas han publicado sus zonas sensibles, aunque la revisión cada cuatro años no se ha realizado en todos los casos.

18 En abril de 2015 España tenía abiertos cuatro expedientes por falta de depuración de aguas residuales que afectaban a unos ochocientos núcleos de población repartidos por todo el país. La Comisión Europea en ese momento presentó una demanda ante el Tribunal de Luxemburgo referida a uno de estos cuatro expedientes y parte de un procedimiento de infracción que se había abierto en 2003. La demanda afecta a siete núcleos de Andalucía, Cataluña y Galicia, cada uno de ellos con más de diez mil habitantes. Se trata de siete "zonas sensibles", que se corresponden con las "aglomeraciones" de Bollullos Par del Condado (Andalucía); Abrera, Berga, Capellades, Figueres y El Terri (Cataluña); y PontevedraMarín-Poio-Bueu (Galicia). nal de Justicia de la UE condenó a España por verter las aguas residuales de 38 zonas urbanas de más de 15.000 habitantes sin tratarlas previamente. Este vertido incontrolado supone un riesgo que infringe la ley sanitaria y medioambiental de la UE, en vigor desde 2000. La condena afecta al Reino de España y no se pronuncia contra las localidades afectadas, lo que obliga al Gobierno de la Nación a cumplir la ley y abre la puerta a sanciones económicas si la Comisión vuelve a denunciar la infracción ante el tribunal comunitario ${ }^{19}$.

El incumplimiento resulta especialmente grave en Andalucía, donde hasta 13 zonas urbanas vierten aguas residuales directamente al mar y la ausencia de depuradoras ha generado problemas de contaminación por aguas fecales en zonas tan sensibles como el Parque Nacional de Doñana; en Galicia, nueve ciudades incumplen la norma (entre ellas Vigo y Santiago, A Coruña ya la cumple este año) y los residuos vertidos al mar han obligado a cerrar al marisqueo algunas rías durante años. La Comunidad Valenciana (6), Canarias (4), Cataluña (2), Asturias (2) y el País Vasco (1) completan las zonas sancionadas por el tribunal comunitario. Finalmente, el 10 marzo de 2016, el Tribunal de J usticia de la Unión Europea dictaminó que España ha incumplido algunas obligaciones en virtud de la directiva de 1991 sobre tratamiento adecuado de aguas residuales urbanas en aglomeraciones de la zona de Pontevedra y en Banyoles (Girona), tal y como denunció la Comisión Europea. En cambio, da la razón a España al no ver incumplimiento de la normativa en las aglomeraciones de Bollullos Par del Condado (Huelva), Abrera y Capellades (Barcelona).

En 2014 se aprobó el Plan de Medidas para el Crecimiento, la Competitividad y la Eficiencia (Plan CRECE) con un objetivo: 2020. El Plan se fundamentaba en la colaboración entre la iniciativa pública y privada, y preveía una movilización de inversiones con cofinanciación europea estimada en 1.000M€, destinados a la ejecución de las infraestructuras de depuración necesarias para dar cumplimiento a las exigencias comunitarias. El objetivo se cifraba en invertir en 400 depuradoras con el fin de mejorar la calidad del agua de los ríos al depurar las aguas procedentes de

19 Tras interponer la denuncia, la Comisión reclamó al Gobierno que cumpliera con el tratamiento de aguas residuales en 2015, horizonte hasta el cual Bruselas no volvería a denunciar al Ejecutivo español. En caso contrario, España podría perder las subvenciones que la UE ofrece a los Estados para la construcción de las depuradoras que exige la ley. 
Tabla 2. Actuaciones e inversiones estimadas, según priorización, hasta 2027

\begin{tabular}{|l|c|c|c|c|}
\hline \multicolumn{1}{|c|}{$\begin{array}{c}\text { PRIORIDADES 1, } 2 \text { Y 3 } \\
\text { AGE + COMUNIDADES AUTÓNOMAS }\end{array}$} & \multicolumn{2}{c|}{ AGE } & \multicolumn{2}{c|}{ COMUNIDADES AUTÓNOMAS } \\
\cline { 2 - 5 } & $\begin{array}{c}\text { NÚMERO } \\
\text { DE ACTUACIONES }\end{array}$ & $\begin{array}{c}\text { NECESIDAD } \\
\text { INVERSIÓN (M€) }\end{array}$ & $\begin{array}{c}\text { NÚMERO } \\
\text { DE ACTUACIONES }\end{array}$ & $\begin{array}{c}\text { NECESIDAD } \\
\text { INVERSIÓN (ME) }\end{array}$ \\
\hline $\begin{array}{l}\text { Procedimiento de infracción Directiva 91/ 271/ CEE ZZNN (P>15.000 hab- } \\
\text { equv). (2004/ 2031) }\end{array}$ & 3 & 115 & 2 & 15 \\
\hline $\begin{array}{l}\text { Procedimiento de infracción Directiva 91/ 271/ CEE ZZSS (P>10.000 hab- } \\
\text { equv). (2002/ 2123) }\end{array}$ & 2 & 70 & 13 & 31 \\
\hline $\begin{array}{l}\text { Procedimiento de infracción Directiva 91/ 271/ CEE ZZNN (2.000<P<15.000 } \\
\text { hab-equv) y ZZSS (2.000<P<10.000 hab-equv). PPAA (2012/ 2100) }\end{array}$ & 101 & 212 & 269 & 635 \\
\hline TOTAL & 106 & 397 & 284 & 681 \\
\hline
\end{tabular}

\begin{tabular}{|l|c|c|}
\hline \multirow{2}{*}{ TOTAL TODAS LAS ADMINISTRACIONES } & NÚMERO DE ACTUACIONES & NECESIDAD INVERSIÓN (M€) \\
\cline { 2 - 3 } & 390 & 1.078 \\
\hline
\end{tabular}

Fuente: Torres, 2014; MAGRAMA / AEAS, 2015.

Gráfico 4. Objetivos ambientales de buen estado de las aguas superficiales para el horizonte 2027

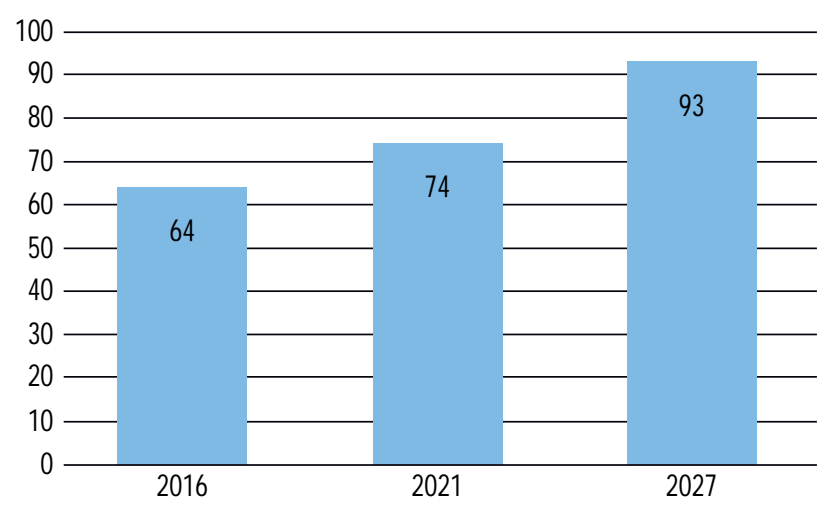

Fuente: Planes Hidrológicos de Cuenca (ler ciclo), AEAS, 2015.

las redes de saneamiento de las ciudades. En el gráfico 4 se observa el objetivo de cumplimiento de la Directiva Marco del Agua propuesto para el horizonte 2027.

Los procedimientos de infracción por incumplimientos que tiene abiertos España por las autoridades europeas han llevado al MAGRAMA a impulsar una priorización en la ejecución de las distintas actuaciones, jerarquizando desde la prioridad mayor (P. 1 y P. 2), para aquellos casos que ya cuentan con sentencia y los que cuentan con dictamen motivado ( $P .3)$, hasta las últimas tres categorías (P. 4, P. 5 y P. 6), que englobarían el resto de actuaciones no incluidas en procedimientos de infracción, pero que pueden considerarse incumplimientos potenciales 0 se enmarcan en el Horizonte Programa de Medidas Planificación Hidrológica 2027. Las actuaciones previstas para dar respuesta a los incumplimientos más graves (máxima prioridad: 1, 2 y 3) y las inversiones estimadas para tal fin por la Administración General del Estado (AGE) y por las Comunidades Autónomas pueden verse en la tabla 2.

Aunque los fondos europeos (Cohesión y Feder) han sido muy importantes para el desarrollo del Plan Nacional de Depuración, las cantidades transferidas desde Europa distan de cubrir las necesidades de inversión del sector. Durante el período
2014-2020, la Unión Europa dotará una financiación de 1.700 M€ (700 serán transferidos a la AGE y 1.000 a las Comunidades Autónomas) para actuaciones que tengan que ver con la conservación del medio ambiente y la protección de la eficiencia de los recursos (Objetivo Temático 6). Los 700 M€ del Estado (que serán gestionados por el MAGRAMA) irán destinados exclusivamente a infraestructuras de saneamiento y depuración (actuaciones correctoras P. 1-P. 3). Sin embargo, los 1000 M€ que gestionarán las Comunidades Autónomas deben destinarse al Objetivo Temático 6, pero no necesariamente para el agua, aunque cabe la posibilidad de que una buena parte se destine a infraestructuras de saneamiento. Queda, sin embargo, todavía un déficit de inversión muy importante para financiar las actuaciones correspondientes al resto de prioridades.

Según Torres ${ }^{20}$, la mayoría de las Comunidades Autónomas tienen canon o figura similar con valores de 0,4/0,5€/ $\mathrm{m}^{3}$. En algunas Comunidades Autónomas el valor es bajo, no existe o falta definición, es el caso de Castilla y León, Andalucía, Galicia y Canarias. El impacto territorial de las medidas a adoptar para cumplir con la Directiva 91/271 es mínimo o nulo en Aragón y Navarra; de entre 0,10-0,15 en Murcia, La Rioja, Asturias, Cataluña y Valencia; de 0,30 o más en Madrid, Castilla y León, Andalucía y País Vasco; el resto se sitúa en un intervalo que va de 0,1 a 0,30. En cualquier caso, el canon resultante final sería del orden de $0,6 / 0,7 € / \mathrm{m}^{3}$ con la excepción de Madrid y País Vasco en donde estaría en $0,8 € / \mathrm{m}^{3}$.

La financiación de los planes de depuración se realiza a partir de la adaptación a la normativa comunitaria europea, la cual requiere inversiones para mantener y actualizar las infraestructuras existentes. La OCDE y la DMA recomiendan la planificación financiera estratégica para asegurar la sostenibilidad y funcionamiento de los servicios de abastecimiento y saneamiento, y para ello, desarrolló el concepto de las 3Ts para la evaluación de estos sistemas ${ }^{21}$. En España, la ejecución de las infraestructuras corre

20 Torres, 2014

21 Las 3Ts se refieren a las vías de financiación de los servicios de agua urbanos: Tarifas (tariffs), tarifas de agua de los usuarios, siempre que se reinviertan en los servicios de agua; Transferencias (transfers), transferencias donantes; en 
a cuenta de la Administración central cuando se consideran de interés general 0 afectan a varias Comunidades Autónomas, y a cuenta de las Comunidades Autónomas o ayuntamientos cuando únicamente afectan a una Comunidad o a los municipios.

El Plan Nacional de Depuración de 1995-2005 determinó las actuaciones para el cumplimiento de las directivas europeas, y aseguraba la correcta gestión de los sistemas de depuración mediante el establecimiento de cánones de saneamiento. Las necesidades inversoras se estimaron en $12.000 \mathrm{M} €$ y, aunque en 2005 no se había ejecutado en su totalidad, se construyeron mil instalaciones depuradoras. El 50\% de los recursos necesarios fueron aportaciones de fondos europeos (Cohesión y Feder), es decir, transferencias, y el $25 \%$ de la AGE (a través de convenios bilaterales con las Comunidades Autónomas) o impuestos.

El Plan Nacional de Calidad de las Aguas, por su parte, estimaba las necesidades de inversión en 19.645 M€, si se incluían las inversiones en I+Dti, desde su aprobación en 2005 hasta el 2015 para afrontar el incumplimiento de la directiva europea 91/271 CEE, la declaración más ambiciosa de zonas sensibles y la Directiva Marco del Agua. La crisis económica que ha sufrido España no ha permitido que se ejecuten ni el $15 \%$ de las inversiones previstas inicialmente. Posteriormente, el MAGRAMA, en 2014, redujo las necesidades inversoras a casi la mitad, 10.000 M€ hasta 2020. Finalmente, los Presupuestos Generales del Estado para 2016 contemplan inversiones para mejorar la calidad de las aguas a través de actuaciones en depuración y saneamiento cifradas en 179, 32 M€. Con tales fondos se financiarán las depuradoras de Gijón (Asturias), Nerja (Andalucía), Ibiza y Santa Eulalia (Baleares), los saneamientos de la comarca agraria de Hervás (Extremadura) o los colectores generales en la ciudad de Ibiza (Baleares). Con el Plan CRECE, se financiarán las depuradoras de Plasencia y Losar de la Vera (Extremadura), Venta de Baños (Castilla y León), los colectores de Almendralejo (Extremadura) y el Mar Menor (Murcia). A lo anterior, hay que sumar los 484 M€ que invertirán las Sociedades Estatales de Agua en actuaciones en materia de abastecimiento y, sobre todo, en depuración. En esta línea, se integran actuaciones como las depuradoras de San Claudio y Villapérez (Asturias), Badajoz (Extremadura), Orense (Galicia), Burgos (Castilla y León) y el saneamiento de Vigo (Galicia) y los interceptores de la ría de Ferrol (Galicia).

\section{Evolución de LA REUTILIZACIÓn PLANIFICAdA En EsPaña}

Los orígenes de la reutilización planificada de las aguas residuales en España son difusos, comenzando sin que existiera ningún tipo de regulación y careciendo, en ocasiones, las aguas residuales de tratamiento alguno. La primera experiencia se produjo en Gran Canaria, a principios de 1970, a través de la EDAR de Barranco Seco I de la ciudad de Las Palmas, empleando el agua regenerada para el uso en riego agrícola. Más tarde, esta práctica se extendió a otros municipios del archipiélago canario, a las islas Baleares y a la Costa Brava. A comienzos de 1980, se construyeron plantas de lagunaje en la Región de Murcia, en po-

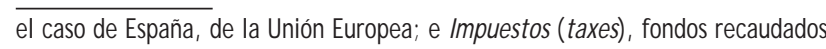
por las autoridades nacionales, locales o regionales a través de los impuestos. blaciones como Lorquí, Ceutí, Alguazas, San Javier y Cartagena, que empleaban el agua tratada para el riego. Estas plantas se convertirían después en depuradoras convencionales, la mayoría con tratamientos terciarios. Posteriormente, los efluentes de grandes depuradoras como las de Benidorm, Alicante y Castellón, en la Comunidad Valenciana, también serían utilizados para la agricultura. En los años noventa se inició el riego de campos de golf con aguas depuradas.

Cabe señalar, en este sentido, que el origen de la reutilización en el ordenamiento jurídico español se remonta a la Ley de Aguas de 1985, que en su artículo 101 determinaba que "el Gobierno establecerá las condiciones básicas para la reutilización de las aguas en función de los procesos de depuración, su calidad y los usos previstos". Tras sucesivas modificaciones de la ley y la aprobación y posterior derogación del Plan Hidrológico Nacional, fue la ley 11/2005 la última que hace referencia a la reutilización antes de que se aprobase el real decreto 1620/ 2007. La ley 11/2005 determinaba que "el Gobierno establecerá las condiciones básicas para la reutilización de las aguas, precisando la calidad exigible a las aguas depuradas según los usos previstos" e incluía que "el titular de la concesión o autorización deberá sufragar los costes necesarios para adecuar la reutilización de las aguas a las exigencias de calidad vigentes en cada momento". En 2009 se redactó un Plan preliminar del Plan Nacional de Reutilización de Aguas, con el horizonte del primer ciclo de planificación hidrológica (2009-2015). Pese a que se estructuró para ser desarrollado junto con el Plan Nacional de Calidad de las Aguas y los Planes Hidrológicos de Cuenca, no llegó a aprobarse. Por lo tanto, el real decreto 1620/2007 siguió siendo la norma básica vigente sobre reutilización de aguas regeneradas.

En efecto, en 2001 se aprobó la ley 10/ 2001, del Plan Hidrológico Nacional (PHN), donde se recoge que "España es un país en el que el agua es un recurso escaso, marcado por graves desequilibrios hídricos debido a su irregular distribución", intentando establecer las bases "para una adecuada planificación de la política hidráulica que se impone como una necesidad, que no puede permanecer aj ena a esta realidad y como un instrumento de superación de la misma". La resolución de estos desequilibrios, según el PHN, debía contemplar un uso armónico y coordinado de todos los recursos hídricos capaces de satisfacer de forma equilibrada los objetivos de la planificación. Con posterioridad, la ley 11/2005, que modifica la anterior sobre el Plan Hidrológico Nacional, afirma que, si bien el trasvase de agua entre cuencas hidrográficas podría suponer a priori una solución para el problema del agua, no es de inminente aplicación para solucionar de manera urgente los problemas actuales, mientras que existen alternativas más prácticas ligadas a la gestión de la demanda, la desalación o la reutilización de recursos, que ayudarían a paliar la demanda de recursos hídricos, evitando entre otros la sobreexplotación y contaminación de acuíferos. Esta norma supuso un fuerte impulso a la reutilización a través del programa nacional "Actuaciones para la Gestión y la Utilización del Agua", conocido como programa AGUA $^{22}$. En él se programaron una serie de actuaciones de mejora

22 En el año 2001 existían en España alrededor de ciento cuarenta sistemas de reutilización, que en 2006 se elevaron a 322 sistemas, y disponían de un caudal 
Tabla 3. Actuaciones de reutilización contempladas en el Programa AGUA

\begin{tabular}{|l|c|}
\hline \multicolumn{1}{|c|}{ Actuaciones } & $\begin{array}{c}\text { Recursos } \\
\text { aportados } \\
\mathrm{hm} \text { /3ñ̃o }\end{array}$ \\
\hline $\begin{array}{l}\text { Actuaciones complementarias de reutilización de } \\
\text { aguas residuales en el Campo de Dalías }\end{array}$ & 20 \\
\hline $\begin{array}{l}\text { Actuaciones de reutilización de aguas residuales en } \\
\text { Almería }\end{array}$ & 10 \\
\hline $\begin{array}{l}\text { Reutilización de aguas residuales en la ciudad de Má- } \\
\text { laga }\end{array}$ & 30 \\
\hline Reutilización de aguas residuales en el Mar Menor & 25 \\
\hline $\begin{array}{l}\text { Reutilización de aguas residuales y obras complemen- } \\
\text { tarias en Villajoyosa y otras zonas anejas }\end{array}$ & 10 \\
\hline $\begin{array}{l}\text { Reutilización de aguas residuales EDAR de Novelda y } \\
\text { Monforte del Cid }\end{array}$ & 5 \\
\hline Reutilización de aguas residuales de la EDAR de Sueca & 10 \\
\hline $\begin{array}{l}\text { Reutilización de aguas residuales depuradas de la Al- } \\
\text { bufera Sur }\end{array}$ & 5 \\
\hline $\begin{array}{l}\text { Reutilización de aguas residuales en el sistema Vina- } \\
\text { lopó-Alicantí }\end{array}$ & 5 \\
\hline $\begin{array}{l}\text { Mejora de depuración y reutilización de aguas residua- } \\
\text { les en la Plana de Castellón }\end{array}$ & 20 \\
\hline $\begin{array}{l}\text { Terminación de la reutilización de las aguas residuales } \\
\text { de Pinedo }\end{array}$ & 30 \\
\hline Total & 170 \\
\hline
\end{tabular}

Fuente: Yagüe Córdova, 2005.

de gestión de aguas, poniendo el énfasis en la reutilización y la desalación, con las que se preveía incrementar los recursos aportados mediante reutilización en $170 \mathrm{hm}^{3} /$ año ${ }^{23}$. Estas actuaciones pueden verse en la tabla 3.

El Plan Nacional de Reutilización de Aguas, 2010-2015 (PNRA) pretendió el apoyo e implicación de las Comunidades Autónomas y Organismos de Cuenca para la financiación y ejecución de las infraestructuras de tratamiento, acumulación y transporte del agua regenerada ${ }^{24}$. El PNRA se marcaba unos ambiciosos objetivos: 1) alcanzar el buen estado que la Directiva Marco del Agua 60/ 2000/ CE imponía para el año 2015; 2) conseguir el "vertido cero" en zonas costeras; 3) sustituir en zonas de interior concesiones de agua prepotable por agua regenerada para los usos en que fuese viable; 4) establecer un modelo de financiación lo suficientemente ágil y dinámico para fomentar el desarrollo de las actuaciones de reutilización de aguas regeneradas; 5) fomentar la reutilización sostenible de aguas regeneradas para los usos agrícola, ambiental, recreativo, industrial y urbano, como una opción viable con respecto al medio ambiente, la seguridad, salud, economía y tecnología disponible; 6) estimar las posibilidades de reutiliza-

concesionado 0 en trámite de obtener la concesión de 506,8 $8 \mathrm{hm}^{3} /$ año.

23 La reutilización está asociada a una depuración previa. En 2005 existían en España más de dos mil quinientas EDAR que depuraban más de $3.375 \mathrm{hm}^{3}$ anuales de aguas residuales. De estas, se estima que se reutilizaban unos cuatrocientos cincuenta $\mathrm{hm}^{3} /$ año, lo que suponía un poco más del trece por ciento del total.

24 Evaluación ambiental estratégica del Plan Nacional de Reutilización de Aguas Regeneradas. Documento inicial. Puede consultarse en: http:// www. mma. es/ secciones/participacion_publica/ eval_amb/ pdf/2009_p_006_documentoinicio.pdf
Mapa 1. Ubicación geográfica de las EDARs con sistemas de reutilización

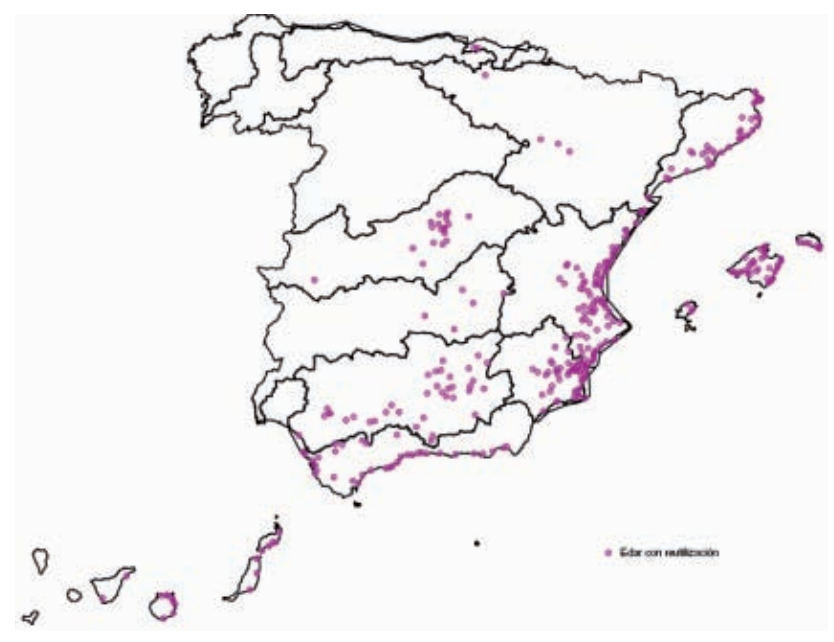

Fuente: CEDEX, 2008.

ción futuras; 7) promover las buenas prácticas de reutilización de aguas regeneradas e, informar, sensibilizar y concienciar sobre los beneficios de la reutilización de agua regenerada.

La reutilización está asociada a una depuración previa. En 2005 existían en España más de dos mil quinientas EDAR que depuraban más de $3.375 \mathrm{hm}^{3}$ anuales de aguas residuales. En el mapa 1 puede verse la ubicación geográfica de los sistemas de reutilización, destacando los que se localizan en el arco mediterráneo, Andalucía y los archipiélagos de Baleares y Canarias, zonas que combinan la existencia de una elevada demanda urbana y/ 0 agrícola de recursos y la enorme dificultad para proveerse en cantidades suficientes de los mismos, debido al agotamiento y deterioro de las fuentes de abastecimiento tradicionales, la progresiva salinización de los acuíferos y al insuficiente régimen de precipitaciones de estos lugares. En el interior de la península, destaca Madrid sobre el resto de las Comunidades Autónomas.

Por su parte, el volumen de aguas depuradas reutilizadas en España en 2006 se situaba en torno a los $368 \mathrm{hm}^{3}$ / año, lo que suponía un 10,8\% del total de los caudales residuales depurados. La distribución regional de los volúmenes reutilizados puede verse en el gráfico 5, donde se aprecia cómo los mayores caudales se usaban en el arco mediterráneo, Andalucía y los archipiélagos de Baleares y Canarias, destacando en especial la Comunidad Valenciana, que reutilizaba 149 hm²/año (40,4\% del total) y la Región de Murcia, que reutilizaba $85 \mathrm{hm}^{3} /$ año $(23,0 \%)^{25}$. La distribución de los $358 \mathrm{hm}^{3} /$ año por Demarcaciones Hidrográficas puede verse en el gráfico 6, destacando las demarcaciones del Júcar (34\%) y Segura $(28 \%)$ del total; y, por detrás, Canarias $(9 \%)$, Cuencas

25 En la Región de Murcia, tras el diseño de un Plan General de Saneamiento y Depuración, en el año 2001, se han ido ejecutando todas las infraestructuras previstas en el mismo, contando, en 2014, con 88 instalaciones de depuración y 47 bombeos que tratan unos ciento diez $\mathrm{hm}^{3} /$ año y dan servicio a más del noventa y nueve por ciento de la población regional. Más del sesenta por ciento de estas instalaciones cuentan con tratamiento terciario avanzado. La inversión que se ha llevado a cabo ha sido superior a los 650 M€ solo en estaciones de depuración y colectores generales. Más del noventa por ciento de agua tratada se reutiliza para el riego en agricultura y como caudales ambientales para el río Segura, que ha pasado de ser el río más contaminado de Europa a que en él se puedan realizar todo tipo de actividades deportivas, incluida la pesca (ESAMUR, 2014). 
Gráfico 5. Distribución por Comunidades Autónomas de los volúmenes reutilizados (en \%) en 2006

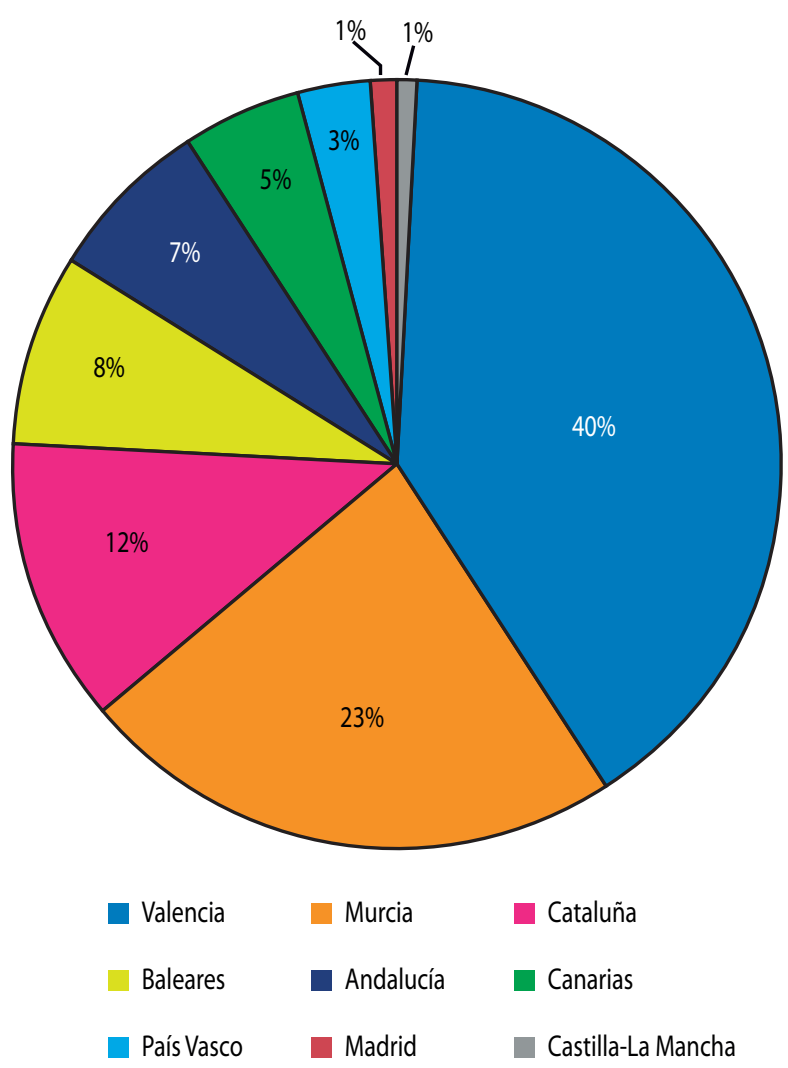

Fuente: CEDEX, 2008.

Interiores de Cataluña (7,5\%), Cuencas Mediterráneas Andaluzas $(7,4 \%)$ y Baleares $(6,3 \%)$.

En el estudio del CEDEX con datos de 2005 y 2006, solo se contemplaban depuradoras de más de $1 \mathrm{hm}^{3} /$ año y no se contabilizaron sistemas de reutilización con menos de $0,2 \mathrm{hm}^{3} /$ año, por lo que puede afirmarse que en la actualidad la capacidad de reutilización es mayor. Los datos globales, publicados por Corrochano en 2008, considerando todas las depuradoras, arrojan una cifra total de $447,3 \mathrm{hm}^{3} /$ año. Las comunidades de Valencia y Murcia han seguido incrementando sus programas de reutilización hasta alcanzar en el caso de la Comunidad Valenciana, en 2010, los $350 \mathrm{hm}^{3} /$ año, cifra que significa un incremento de más del doble respecto a las cantidades de $2008^{26}$.

\section{Usos del agua regenerada en España}

Los usos que se le pueden dar a las aguas regeneradas son muchos y variados. Los cinco principales a los que se destina el

26 Es de destacar, en el caso de la Comunidad Valenciana, el Plan de reutilización de Aguas en el área metropolitana de Valencia que consiste en la ampliación de la capacidad de siete depuradoras y la modernización y mejora de los sistemas de tratamiento en las conducciones necesarias para transportar el agua depurada al lugar de uso, así como en la construcción de colectores para desconectar totalmente los sistemas de alcantarillado y las infraestructuras de riego. El coste de estas actuaciones asciende a unos ciento cuarenta $M €$, que generaran unos ciento cincuenta $\mathrm{hm}^{3} /$ año de agua regenerada para regar la huerta de Valencia y mantener la Albufera.

\section{Gráfico 6. Distribución por Demarcaciones Hidrográficas de los volúmenes reutilizados (en \%) en 2006}
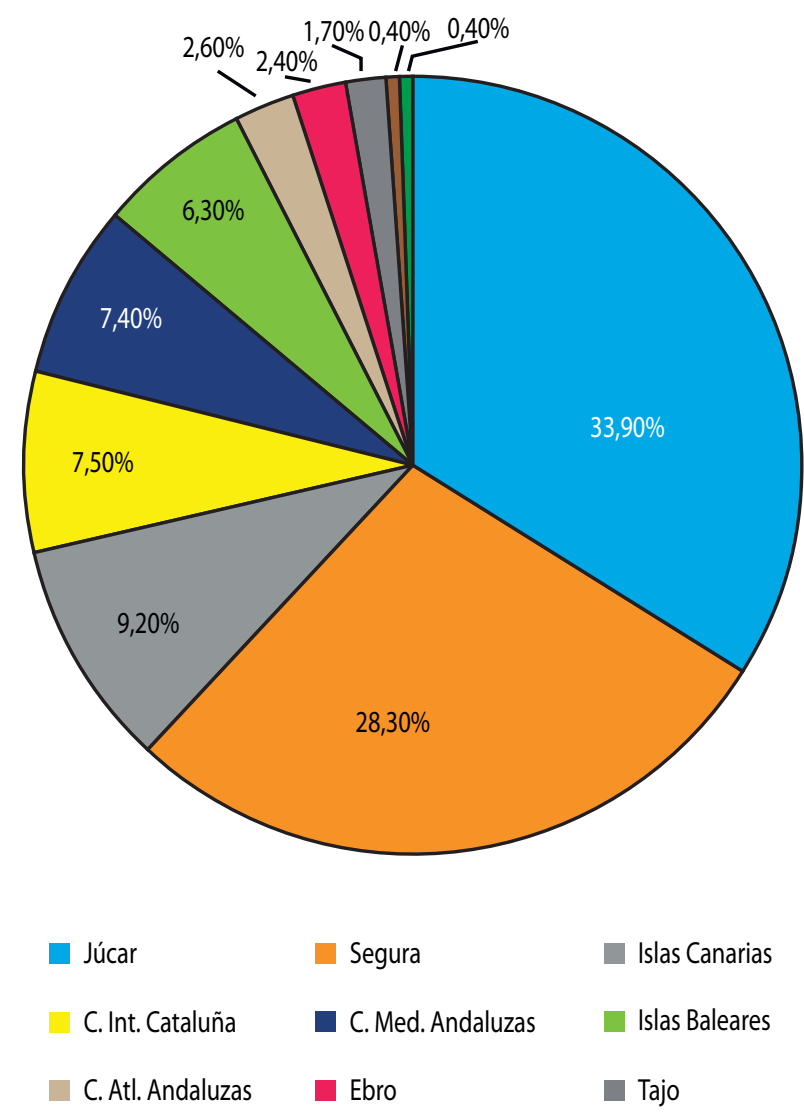

Guadalquivir

Guadiana

Fuente: CEDEX, 2008.

agua regenerada en España están representados en el gráfico 7. En primer lugar -y a mucha diferencia de los demás- figura el agrícola, con más del setenta por ciento del total del destino de las aguas regeneradas y un volumen anual de $261 \mathrm{hm}^{3} /$ año, que se utilizan para el riego de productos de consumo humano en fresco, pastos, agricultura, cultivos leñosos, ornamentales, viveros y forrajes, entre otros. Según el informe del CEDEX, en este caso no se incluyen en el uso agrícola aquellos riegos que están utilizando agua bruta, como las zonas forestales, los cuales deben adecuarse a las calidades exigibles por el real decreto 1620/ 2007. Contado estos volúmenes se alcanzarían los $310 \mathrm{hm}^{3} /$ año. Es sin duda el uso que más puede contribuir al ahorro de agua superficial y/ o subterránea, y, por tanto, ayudar a la conservación del medio natural. Al uso agrícola le sigue en importancia el ambiental, al que se destina más del diecisiete por ciento de los caudales reutilizados, que sirven para la recarga y recuperación de acuíferos, el riego de bosques y zonas verdes, la silvicultura, la restauración y mantenimiento de humedales, las infiltraciones para evitar la intrusión salina o la restitución de caudales ecológicos. El uso recreativo, con el 7\%de los caudales, constituye el siguiente aprovechamiento en importancia, destinándose los volúmenes principalmente en este caso al riego de campos de golf, aunque 
Gráfico 7. Distribución por usos del agua regenerada en España

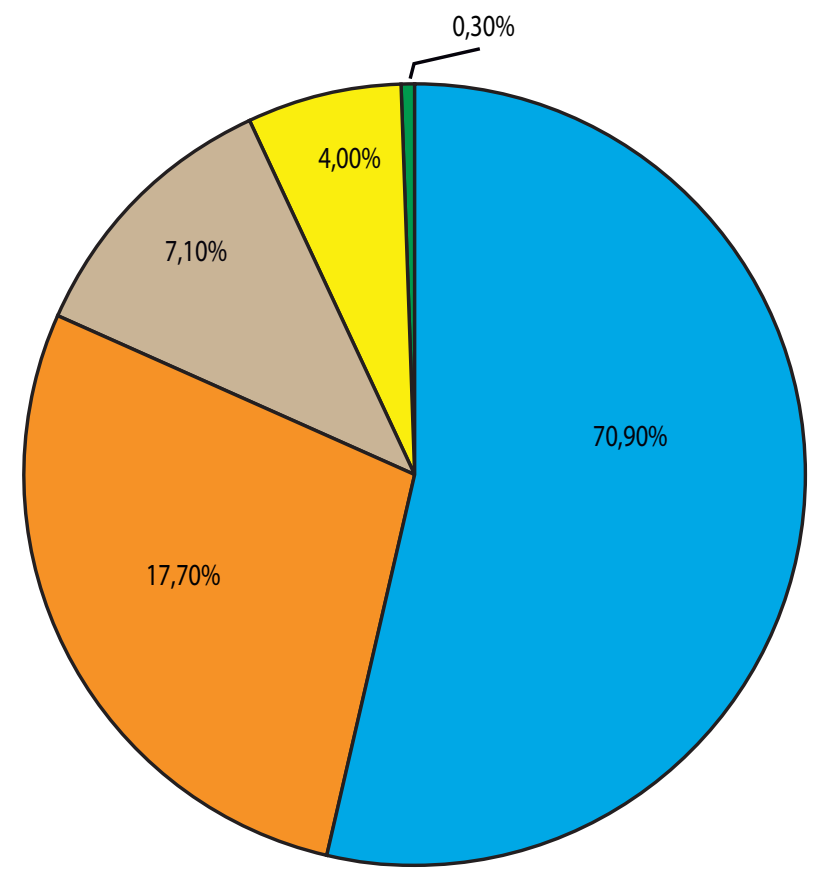

Agrícola

Ambiental

Recreativo

Fuente: CEDEX, 2008.

también a estanques 0 caudales circulantes ornamentales ${ }^{27}$. El $4 \%$ se dedica al aprovechamiento urbano (residencial, jardines privados, descargas de aparatos sanitarios) y servicios (riego de zonas verdes, limpieza de calles, sistemas contra incendios, lavado industrial de coches); mientras que solo una exigua cantidad, el $0,3 \%$ del total, es para aprovechamiento industrial (aguas de proceso y limpieza, refrigeración, condensadores). Resulta fundamental que las administraciones regionales impulsen e incluso obliguen cuando sea aconsejable al uso de aguas residuales depuradas cuando su aprovechamiento lo permita, sobre todo en los espacios que se ven afectados por déficit permanente ${ }^{28}$.

Del caudal reutilizado total $\left(368 \mathrm{hm}^{3} /\right.$ año), solo el $61 \%(223,7$ $\mathrm{hm}^{3} /$ año) cuenta con un tratamiento de regeneración, mientras que el 39\% restante carece de él, reutilizándose con una calidad de tratamiento secundario. Debe tenerse en cuenta, en este sentido, que la entrada en vigor del real decreto 1620/ 2007 obligaba a construir tratamientos de regeneración en los casos en que no exista y a adecuar alguna de las estaciones regeneradoras existentes para que su efluente se adapte a las calidades de uso exigidas ${ }^{29}$. A escala nacional, las estaciones depuradoras de las que toman agua los sistemas de reutilización tratan $1.757 \mathrm{hm} 3 /$ año, 10

27 Para el riego de campos de golf se prevé un importante crecimiento de las aguas regeneradas destinadas a este fin, ya que existen en la actualidad en España unos trescientos campos de golf con unas necesidades hídricas de unos ochenta $\mathrm{hm}^{3} /$ año y en casi todas las Comunidades se está regulando con el fin de obligar a que estas instalaciones se abastezcan con estos recursos, como es el caso de la Comunidad Valenciana a través de la ley 9/2006.

28 Melgarej0, 2009

29 Idem.

Gráfico 8. Evolución de la reutilización de agua en España (hm3/ año)

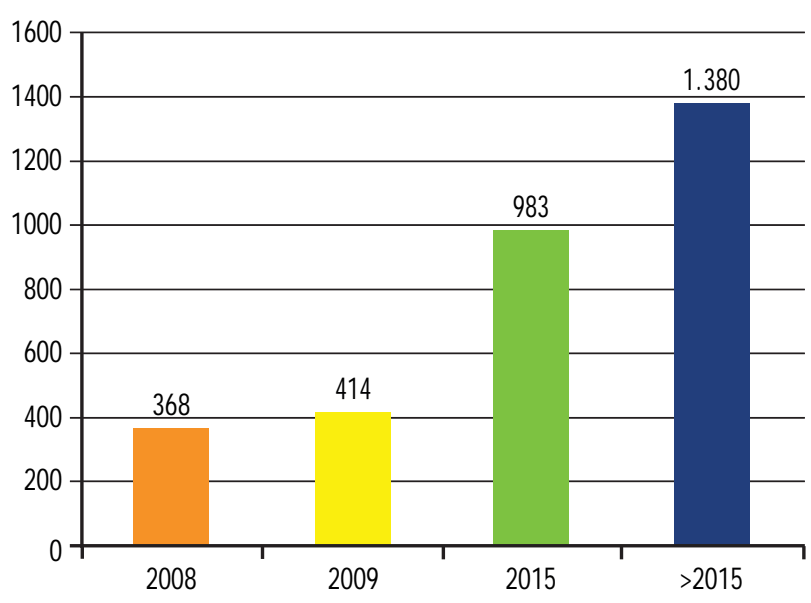

Fuente: Yagüe Córdova, 2014.

que representa el $69 \%$ de su capacidad total $\left(2.546 \mathrm{hm}^{3} /\right.$ año). La capacidad de las estaciones regeneradoras en funcionamiento en 2006 fue de 706,6 hm³/ año, lo que supone un 40\%sobre el caudal depurado. En cuanto al volumen de agua reutilizada, $368 \mathrm{hm}^{3} /$ año supone un $52 \%$ sobre la capacidad de regeneración en funcionamiento y un $21 \%$ sobre el caudal de agua residual depurado $0^{30}$. Por lo tanto, teniendo en cuenta que del volumen reutilizado un $60,75 \%$ pasa por una estación regeneradora, podría deducirse que los sistemas de reutilización actuales podrían incrementar en un $68,34 \%$ los volúmenes de agua regenerada si existieran nuevas demandas en su zona de influencia. En todo caso hay que tener en cuenta la estacionalidad de la demanda del uso de riego agrícola, por lo que las capacidades de regeneración en este tipo de sistemas son notablemente superiores a los volúmenes regenerados, lo que hace difícil determinar el sobredimensionamiento actual de las estaciones regeneradoras. Con todo, la evolución del consumo de este tipo de caudales y las previsiones que se estiman para el futuro son claramente alcistas, como puede apreciarse en el gráfico 8.

\section{COSTES DE LA DEPURACIÓN Y REUTILIZACIÓN}

En el marco de la Unión Europea no se dispone de subvenciones concretas para fomentar la reutilización de agua ${ }^{31}$. Los mecanismos existentes se pueden agrupar en dos categorías: los que financian los costes iniciales y los que se aplican a los costes de explotación. En España no existe un mercado de agua regenerada, por lo que resulta difícil obtener un precio para este pro-

30 En 2008 la reutilización de aguas depuradas en la Comunidad Valenciana era de las más importantes de España, alcanzándose la cifra de $225 \mathrm{hm}^{3} /$ año, que se han utilizado principalmente en el regadío. Esta cifra representa el $45 \%$ del agua tratada generada en las depuradoras (512 hm³ año). $154 \mathrm{hm}^{3}$ han sido reutilizados directamente $\left(30 \%\right.$ ), el resto, $71 \mathrm{hm}^{3}$, han sido obtenidos mediante la aplicación de tratamientos terciarios, que en ocasiones son complementados por procesos de desalinización, como, por ejemplo, en la EDAR de Benidorm, procedentes de 32 EDARs que tienen incorporados estos tratamientos avanzados (coagulación-floculación, filtración y algunas ultravioletas y/ o ósmosis inversa) (Melgarejo, 2009).

31 Hernández et al, 2006. 
ducto; por eso, se asume que el coste por metro cúbico debe ser igual al precio máximo de venta, garantizando así la cobertura de los gastos. Para favorecer la reutilización, resulta imprescindible establecer una política de precios que reparta los costes de la regeneración y la gestión de las aguas residuales entre la totalidad del consumo, estableciendo incentivos para lograr que en todos los sectores se utilice agua regenerada cuando esto sea posible.

El coste unitario del agua se define como el cociente entre los importes abonados por el suministro de agua más los abonados en concepto de alcantarillado, depuración y cánones de saneamiento 0 vertido, y el volumen de agua registrada y distribuida a los usuarios. En 2013 el coste unitario del agua se situó en $1,83 € / \mathrm{m}^{3}$. El suministro alcanzó los $1,09 € / \mathrm{m}^{3}$, mientras que el saneamiento (alcantarillado, depuración, cánones de sanea-

Tabla 4. Coste unitario del agua $\left(€ / \mathrm{m}^{3}\right)$ por Comunidades Autónomas en 2013

\begin{tabular}{|l|c|c|c|}
\cline { 2 - 4 } \multicolumn{1}{c|}{} & Total & Suministro & Saneamiento \\
\hline Andalucía & 1,74 & 1,04 & 0,7 \\
\hline Aragón & 1,46 & 0,7 & 0,76 \\
\hline Asturias & 1,32 & 0,68 & 0,64 \\
\hline Baleares & 2,21 & 1,11 & 1,1 \\
\hline Canarias & 2,03 & 1,66 & 0,37 \\
\hline Cantabria & 1,56 & 0,91 & 0,65 \\
\hline Castilla y León & 1 & 0,54 & 0,46 \\
\hline Castilla-La Mancha & 1,28 & 0,79 & 0,49 \\
\hline Cataluña & 2,54 & 1,34 & 1,2 \\
\hline Comunidad Valenciana & 2,03 & 1,23 & 0,8 \\
\hline Extremadura & 1,49 & 1,04 & 0,45 \\
\hline Galicia & 1,19 & 0,77 & 0,42 \\
\hline Madrid & 2,02 & 1,28 & 0,74 \\
\hline Murcia & 2,73 & 1,86 & 0,87 \\
\hline Navarra & 1,47 & 0,73 & 0,74 \\
\hline País Vasco & 1,52 & 0,75 & 0,77 \\
\hline La Rioja & 1,06 & 0,5 & 0,56 \\
\hline Ceuta y Melilla & 1,95 & 1,37 & 0,58 \\
\hline Coste unitario medio & 1,83 & 1,09 & 0,74 \\
\hline
\end{tabular}

Fuente: INE, 2015.

miento y vertido) fue de $0,74 € / \mathrm{m}^{3} 32$. Los valores más elevados del coste unitario del agua en 2013 se dieron en Región de Murcia $(2,73$ euros por metro cúbico), Cataluña $(2,54)$ y Baleares $(2,21)$. Por el contrario, Castilla y León $(1,00)$, La Rioja $(1,06)$ y Galicia $(1,19)$ presentaron los costes más bajos. El conjunto de los costes unitarios del agua por Comunidades Autónomas puede verse en la tabla 4.

¿Cuáles son los costes de depurar y reutilizar el agua? Hay que comenzar señalando que los costes de los procesos de depuración y reutilización de aguas están condicionados por la existencia de varios factores. En primer lugar, ha de tenerse en cuenta el tipo

32 INE, 2015. de agua a depurar, dado que su procedencia determina la clase y el nivel de agentes contaminantes que se deben eliminar y el tipo de tratamiento que se ha de aplicar. En segundo lugar, tiene que considerarse el uso al que se destina este agua, porque según sea se aplicarán unos procesos u otros para que se cumplan las calidades exigidas por el mismo. Existe una enorme variabilidad de los costes asociados a los distintos tratamientos, pudiendo afirmarse que aumentan a medida que conllevan un mayor número de procesos. Algunos usos, como son los de reutilización industrial y los que se destinan a la recarga de acuíferos, también presentan importantes variaciones de precio. Especial atención merece el tema de los costes energéticos, ya que el consumo es muy desigual (y, por lo tanto, el coste) según la técnica elegida. Así, hay que tener en cuenta que existe una correlación entre el grado de contaminación del agua tratada (medida por el cociente entre los h-e servidos y los metros cúbicos procesados) y el consumo de energía de la planta.

En términos generales, para un tratamiento físico-químico los costes de inversión oscilan entre 20 y 30 euros/ $\mathrm{m}^{3} /$ día instalado y los de operación se sitúan entre 0,02 y 0,03 euros/ $\mathrm{m}^{3}$; para la filtración sobre lecho de arena los costes de inversión fluctúan entre 55 y 100 euros/ $\mathrm{m}^{3}$ / día instalado y los de operación pueden representar entre 0,01 y 0,03 euros/ $\mathrm{m}^{3}$; y para una desinfección con rayos ultravioleta los costes de inversión pueden variar entre 7,5 y 8,6 euros/ $\mathrm{m}^{3} /$ día instalado y los de operación entre 0,01 y 0,02 euros/ $\mathrm{m}^{3}$. Los procesos de microfiltración (MF), ultrafiltración (UF), ósmosis inversa (OI) y electrodiálisis reversible (EDR) se incorporan cada vez más al tratamiento de aguas residuales, moviéndose sus costes de inversión entre 200 y 400 euros/ m³ día tratado, mientras que los de explotación varían entre 0,05 y 0,09 euros $/ \mathrm{m}^{3}$, o sea son del orden o ligeramente superiores al tratamiento convencional, dependiendo de la calidad del efluente secundario $0^{33}$.

En la Comunidad Valenciana, según los datos obtenidos de la EPSAR (Entidad Pública de Saneamiento de Aguas Residuales) de la Comunidad Valenciana, para 2009, los costes de depuración ascienden a un total de $0,220 € / \mathrm{m}^{3}$, que se distribuyen del modo siguiente: los costes de personal ascienden a 0,088 €/ $\mathrm{m}^{3}(40 \%)$; los de la energía, 0,042 €/ $\mathrm{m}^{3}(19 \%)$; los de residuos, 0,035 €/ $\mathrm{m}^{3}$ $(16 \%)$; los de mantenimiento, $0,026 € / \mathrm{m}^{3}(12 \%)$; los de reactivos, $0,015 € / \mathrm{m}^{3}(7 \%$, y, bajo el epígrafe de varios (material de laboratorio, vehículos, combustible, jardinería, etc. ), se contabilizan gastos por $0,014 € / \mathrm{m}^{3}(6 \%$. Por su parte, los costes de explotación difieren de manera sensible atendiendo a los distintos tratamientos. Así, ascienden a $0,26 € / \mathrm{m}^{3}$ con tratamiento secundario; a $0,06 € / \mathrm{m}^{3}$, con tratamiento terciario; y a $0,14 € / \mathrm{m}^{3}$, con tratamientos avanzados. El coste de la distribución se establece en 0,1 $€ / m^{34}$. La estructura de costes de la depuración y reutilización en la Comunidad Valenciana correspondiente a 2015 puede verse en el gráfico 9.

33 Prats y Melgarejo, 2006

34 Melgarejo, 2009. 
Gráfico 9. Estructura de costes de la depuración y reutilización en la Comunidad Valenciana en 2015

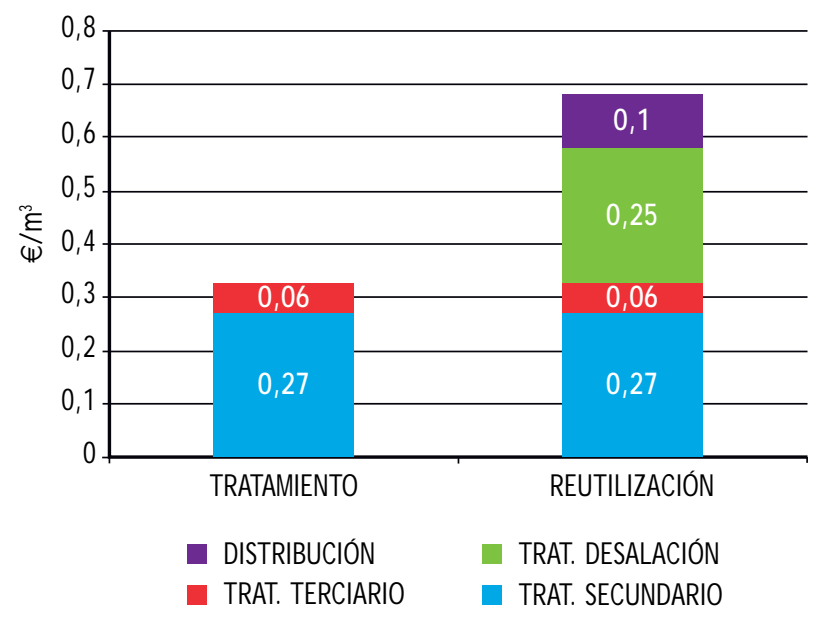

Fuente: EPSAR, 2015.

\section{Conclusiones}

La incorporación de España a la CEE en 1986 implicó la adaptación a la normativa europea sobre depuración, más exigente que la española. Así, la aprobación en 1991 de la Directiva 91/271/CEE sobre depuración de aguas residuales supuso la obligación de disponer de colectores que recogieran las aguas residuales generadas por las aglomeraciones urbanas, y estableció los tratamientos necesarios en función del emplazamiento donde se vertían, clasificando las zonas en "sensibles", "menos sensibles" o "normales", con el objetivo de reducir los niveles de contaminación de las aguas superficiales.

En 1995 se aprobó el Plan Nacional de Depuración, que precisaba las actuaciones que debían llevarse a cabo para el cumplimiento de las exigencias europeas. Además de señalar las depuradoras que había que construir, ampliar, completar o adaptar, el Plan perseguía la correcta gestión de los sistemas de depuración mediante la creación de entes supramunicipales de gestión y el establecimiento de cánones de saneamiento. En toda España, en 1995, se habían construido 500 depuradoras (aunque no todas cumplían las exigencias de la Directiva) y el nivel de cobertura era del $40 \%$ en relación a la totalidad de la carga contaminante expresada en habitantes equivalentes. Entre 1995 y 2005, se construyó y aseguró el mantenimiento de mil depuradoras, alcanzando una cobertura del $80 \%$ en 2005, lo que mejoró considerablemente la calidad del agua de los ríos y la costa.

En el año 2000 entró en vigor la Directiva Marco del Agua, que pretendía unificar las actuaciones de la Unión Europea y alcanzar un "buen estado" de las masas de agua para 2015. La respuesta a las nuevas exigencias europeas fue la aprobación en 2005 del Plan Nacional de Calidad de las Aguas, que se diseñó con el mismo horizonte temporal que la DMA y tenía el objetivo de lograr el total cumplimiento de los requerimientos europeos.

Una gestión adecuada del agua requiere un equilibrio entre sus valores económicos y sus valores medioambientales, sociales y culturales. La DMA establece un nuevo modelo de uso del agua que puede denominarse modelo medioambiental o de crecimien- to sostenible, en contraposición con los modelos tradicionales de desarrollo de la oferta y en línea con algunos aspectos de los modelos de gestión de la demanda. En los modelos de crecimiento sostenible se debe de potenciar y estimular el uso de tecnologías más eficientes, tanto desde un punto de vista ambiental como económico. Bajo esta nueva concepción, la calidad del agua es una restricción para el desarrollo de la actividad económica y los precios del recurso deben ser fijados de forma que, además de englobar el coste de oportunidad, reflej en la escasez y los daños producidos en el medio.

En la actualidad, España no cumple con la legislación comunitaria en materia de depuración del agua urbana. El nivel de cobertura es cercano al $90 \%$ del total en relación con la carga contaminante, pero está especialmente alejado de cumplir los objetivos que fija la DMA para la depuración en municipios de más de 10.000 habitantes, ya que solo el $32 \%$ de estos municipios españoles cuenta con los sistemas de depuración terciarios que exige la legislación comunitaria 35.

Dos son los aspectos hacia donde debe encaminarse la gestión en el futuro: uno, la aplicación de nuevas tecnologías que impliquen menos costes energéticos, que sean más amigables con el entorno, que generen menos residuos, en definitiva, que sean más sostenibles; $y$, dos, un cambio en el modelo de financiación, con mayor protagonismo de los cánones de saneamiento y una revisión profunda de las tarifas del agua, que garantice el cumplimiento del principio de recuperación de costes.

En este nuevo modelo, la potencialidad de la reutilización de aguas es un hecho incontrovertible, sobre todo en países con problemas de escasez como es el caso de España, pero su consolidación como recurso no convencional estratégico es un reto que obliga a todos los actores con responsabilidad en el tema a actuar de forma coordinada y con absoluto rigor en la planificación de las actuaciones futuras. El real decreto 1620/2007 por el que se establece el régimen jurídico de la reutilización ha supuesto un avance importante en la regulación de la reutilización, al clarificar tanto las responsabilidades de las Administraciones Públicas como las correspondientes a los concesionarios y usuarios finales, y al establecer los criterios de calidad para cada uno de los posibles usos de estos caudales. Ahora bien, sigue siendo necesario que se habiliten mecanismos para potenciar la reutilización y la adecuación de los sistemas existentes a las exigencias de calidad más estrictas.

Con todo, hay que tener en cuenta que el aumento de los volúmenes depurados no va a significar un incremento automático de la reutilización, por cuanto existen diversos factores que pueden frenar su extensión. Cabe destacar, en este sentido, la falta de regularidad en la calidad del efluente depurado en algunas EDARs; la necesidad de utilizar los efluentes depurados para garantizar los caudales ecológicos, especialmente en los momentos de estiaje o épocas de sequía; la dificultad de convertir las demandas potenciales en reales, especialmente en el caso de la reutilización en riego agrícola, debido a la resistencia de los agricultores a sustituir los recursos tradicionales por el agua regene-

35 Price Water House Coopers, 2014. 
rada; y, por último, la ausencia de una cultura de la planificación en la toma de decisiones respecto a las actuaciones de reutilización, que implica la adopción de iniciativas sin los necesarios estudios de viabilidad.

\section{Bibliografía}

AEAS-CONAMA. 2015: Hacia un funcionamiento económicamente competitivo, sostenible y alternativo en la gestión de las aguas residuales en España. GT-14 Aguas Residuales. CONAMA 2014-Congreso Nacional del Medio Ambiente (en http:// anavam.com/ docs/ congreso-12-GT-14_hacia-un-funcionamiento-economicamentecompetitivo,-sostenible-y.pdf).

Cajigas Delgado, Á. 2012: "La evolución de la depuración de las aguas residuales urbanas en España", en Ingeniería Civil, 168, 9-20.

CEDEX, 2008: Realización de una base de datos sobre los sistemas de reutilización de aguas depuradas en España. Madrid.

COMISIÓN EUROPEA. 2013: Informe de la Comisión al Parlamento Europeo, al Consejo, al Comité Económico y Social Europeo y al Comité de las Regiones. Séptimo informe de la Comisión sobre la aplicación de la Directiva sobre el tratamiento de las aguas residuales urbanas (91/271/CEE) en http:// eurlex. europa.eu/ legalcontent/ ES/ TXT/ PDF/ ?uri=CELEX:52013DC0574\&fromEN

Corrochano Codorniu, A. 2008: "Nuevo Real Decreto sobre reutilización de aguas depuradas", en Ambienta, 76, 38-42.

ESAMUR (Entidad Regional de Saneamiento y Depuración de Aguas Residuales). 2014: Memoria de actividades. Murcia.

Hernández, F., De Las Fuentes, L. y Urkiaga, A. 2006: Guía para la realización de estudios de viabilidad en proyectos de reutilización de aguas depuradas. AQUAREC, MIMAM y Ministerio de Fomento.

INE. 2015: Encuesta sobre el Suministro y Saneamiento del Agua. Año 2013.
MAGRAMA. 2007: Plan Nacional de Calidad de las Aguas: Saneamiento y Depuración (2007-2015). PNCA. (en www.magrama.gob.es/es/ agua/ planesestrategias/PlanNacionalCalidadAguas_tcm7-29339. pdf).

MAGRAMA. 2010: Plan Nacional de Reutilización de Aguas (Versión preliminar).

MAGRAMA. 2012: Informe de Sostenibilidad en España. OSE (en http:// www. upv. es/ contenidos/ CAMUNISO/ info/ U0637061. pdf).

MAGRAMA. 2014: Informe de Sostenibilidad en España, 2014, en http:// www. upv. es/ contenidos/ CAMUNISO/ info/ U0679775. pdf.

Melgarejo, J. 2009: "Efectos ambientales y económicos de la reutilización del agua en España", en Clm. Economía, 15, 245-270.

Melgarejo, J., Prats, D. y de Santiago, F. 2015: "El Consorcio de Aguas de la Marina Baja", en A. Ortuño: Cómo se gestiona una ciudad. Alicante, Publicaciones de la Universidad de Alicante, 189-213.

Molina, A. y Melgarej0, J. 2015: "Water policy in Spain: seeking a balance between transfers, desalination and wastewater reuse", en International J ournal of Water Resources Development, 32, 781-798, en: D0l10.1080/ 07900627.2015.1077103.

Prats, D. y Melgarejo, J. 2006: Desalación y reutilización de agua. Situación en la provincia de Alicante. Alicante, Fundación COEPA.

Price Water House Coopers. 2014: "La gestión del agua en España, análisis de la situación actual del sector y retos futuros". ACCIONA (en http:// www. acciona.com/legacyMedia/1226705/informe_gestion_agua.pdf).

Torres Sánchez, G. 2014: Situación de la depuración de las aguas urbanas en España. MAGRAMA.

Yagüe Córdova, J. 2005: "Regeneración y Reutilización de aguas en el marco del Programa A.G.U. A." J ornadas técnicas La integración del agua regenerada en la gestión de los recursos: El papel dinamizador del territorio. Lloret de Mar, 19 y 20 octubre de 2005.

Yagüe Córdova, J. 2014: Plan Nacional de Reutilización de Aguas. MAGRAMA (en http:/ / www.lis. edu. es/ uploads/ 12fce39e_4a31_4166_ a2e7_888f6ce1259a.pdf). 